\title{
Changing nucleotide specificity of the DEAD-box helicase Hera abrogates communication between the Q-motif and the P-loop
}

\author{
Julian Strohmeier ${ }^{1}$, Ines Hertel ${ }^{2}$, Ulf Diederichsen ${ }^{1}$, \\ Markus G. Rudolph ${ }^{3}$ and Dagmar Klostermeier ${ }^{2, a}, *$ \\ ${ }^{1}$ Institute for Organic and Biomolecular Chemistry, \\ University of Göttingen, D-37077 Göttingen, Germany \\ ${ }^{2}$ Division of Biophysical Chemistry, Biozentrum, \\ University of Basel, CH-4056 Basel, Switzerland \\ ${ }^{3}$ F. Hoffmann-La Roche, CH-4070 Basel, Switzerland \\ * Corresponding author \\ e-mail: dagmar.klostermeier@unibas.ch
}

\begin{abstract}
DEAD-box proteins disrupt or remodel RNA and protein/ RNA complexes at the expense of ATP. The catalytic core is composed of two flexibly connected RecA-like domains. The N-terminal domain contains most of the motifs involved in nucleotide binding and serves as a minimalistic model for helicase/nucleotide interactions. A single conserved glutamine in the so-called Q-motif has been suggested as a conformational sensor for the nucleotide state. To reprogram the Thermus thermophilus RNA helicase Hera for use of oxoATP instead of ATP and to investigate the sensor function of the Q-motif, we analyzed helicase activity of Hera Q28E. Crystal structures of the Hera N-terminal domain Q28E mutant (TthDEAD_Q28E) in apo- and ligand-bound forms show that Q28E does change specificity from adenine to 8oxoadenine. However, significant structural changes accompany the Q28E mutation, which prevent the P-loop from adopting its catalytically active conformation and explain the lack of helicase activity of Hera_Q28E with either ATP or 8-oxo-ATP as energy sources. 8-Oxo-adenosine, 8-oxo-AMP, and 8-oxo-ADP weakly bind to TthDEAD_Q28E but in noncanonical modes. These results indicate that the Q-motif not only senses the nucleotide state of the helicase but could also stabilize a catalytically competent conformation of the Ploop and other helicase signature motifs.
\end{abstract}

Keywords: crystal structure; Hera; hydrogen bond network; nucleotide specificity; 8-oxo-adenosine; ribosome biogenesis.

\section{Introduction}

RNA helicases couple the chemical energy from ATP hydrolysis to structural rearrangements of RNA and RNA/protein

aPresent address: Institute for Physical Chemistry, University of Muenster, Corrensstrasse 30, D-48149 Muenster, Germany. complexes. As such they touch upon virtually all processes of RNA metabolism including transcription, translation, RNA editing, viral replication, and ribosome biogenesis (Cordin et al., 2006). DEAD-box proteins form the largest RNA helicase family (Hilbert et al., 2009). They are named according to the characteristic sequence of their Walker B motif, which is implicated in ATP binding. DEAD-box proteins share a common modular architecture (Figure 1A): a helicase core of two flexibly connected RecA-like domains (RecA_N and RecA_C), which are sometimes flanked by additional domains that confer substrate binding specificity, mediate protein/protein interactions or may contribute to duplex separation (Tsu et al., 2001; Kossen et al., 2002; Grohman et al., 2007; Linden et al., 2008; Mohr et al., 2008; Del Campo et al., 2009). In addition, DEAD-box helicases can also form dimers (Klostermeier and Rudolph, 2009; Rudolph and Klostermeier, 2009) via dedicated dimerization domains, as has recently been found for the Thermus ther-

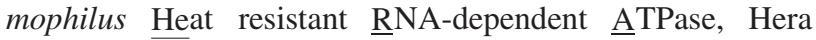
(Morlang et al., 1999), a DEAD-box RNA helicase presumably involved in ribosome assembly and assembly of RNase P (Linden et al., 2008). Upon cooperative binding of RNA and ATP (or an ATP analog), the helicase core collapses to form a composite RNA binding site traversing both RecA-like domains, as exemplified by crystal structures of helicase/ RNA complexes (Andersen et al., 2006; Bono et al., 2006; Sengoku et al., 2006; von Moeller et al., 2009). The RecA_N domain of DEAD-box proteins contains most of the conserved sequence motifs required for nucleotide binding, such as the Q-motif and the P-loop (or Walker A motif), and the DEAD-box which connects the P-loop to the SAT motif (Figure 1A). RecA_N can thus serve as a minimalistic model to study nucleotide binding to RNA helicases (Rudolph et al., 2006; Hilbert et al., 2010).

Based on mutational analyses and sequence comparisons, the Q-motif has been defined as a stretch of nine amino acids with an almost invariant (99\%) glutamine (Benz et al., 1999; Tanner, 2003; Tanner et al., 2003). Crystal structures of helicase/nucleotide complexes showed that the glutamine side chain directly binds to the adenine base of the nucleotide via a double hydrogen bond (Figure 1B). Such a glutamine is also present in reverse gyrases from extremophiles and in several other ATP-binding P-loop containing proteins, such as viral packaging motors and endonucleases, but also in proteins involved in ATP synthesis and chromosome segregation (Iyer et al., 2004; Draper and Rao, 2007; Tsay et al., 2009). It was suggested that the Q-motif may be a conformational sensor for nucleotide binding, relaying the signal of a bound nucleotide to the P-loop (Cordin et al., 2004). A 


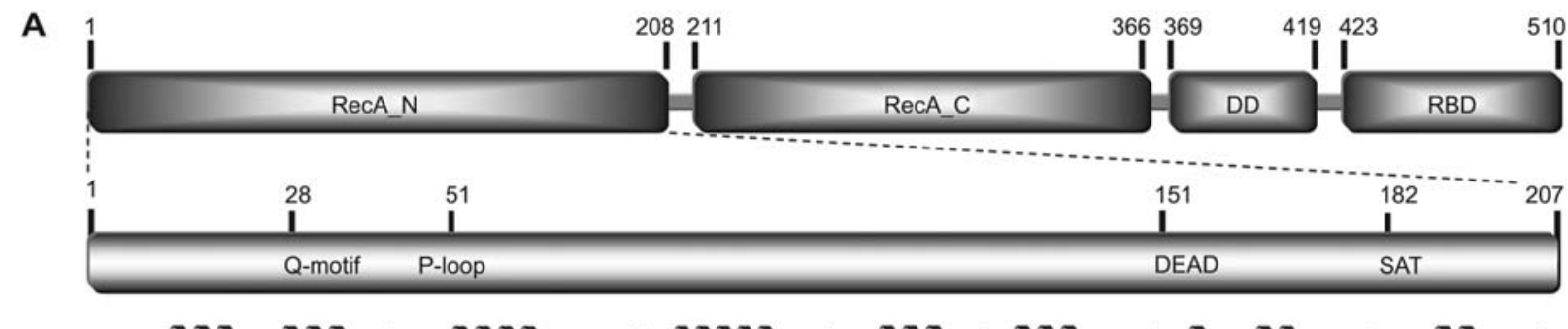

B<smiles></smiles>

DEAD-box proteins

Adenine

GTP-binding proteins

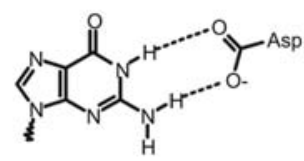

Guanine

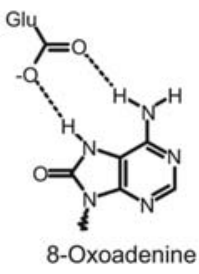

等

Xanthine
C

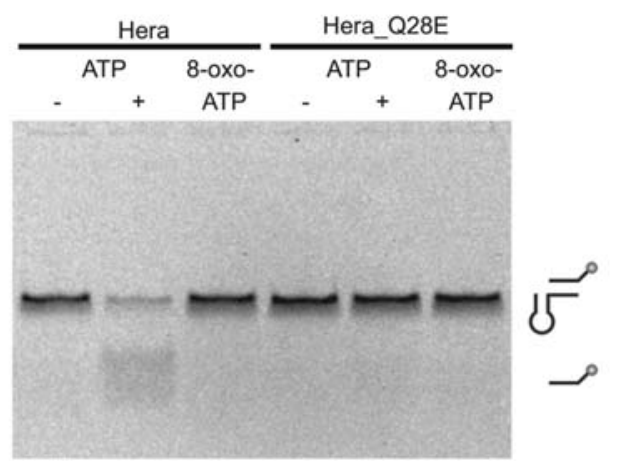

D

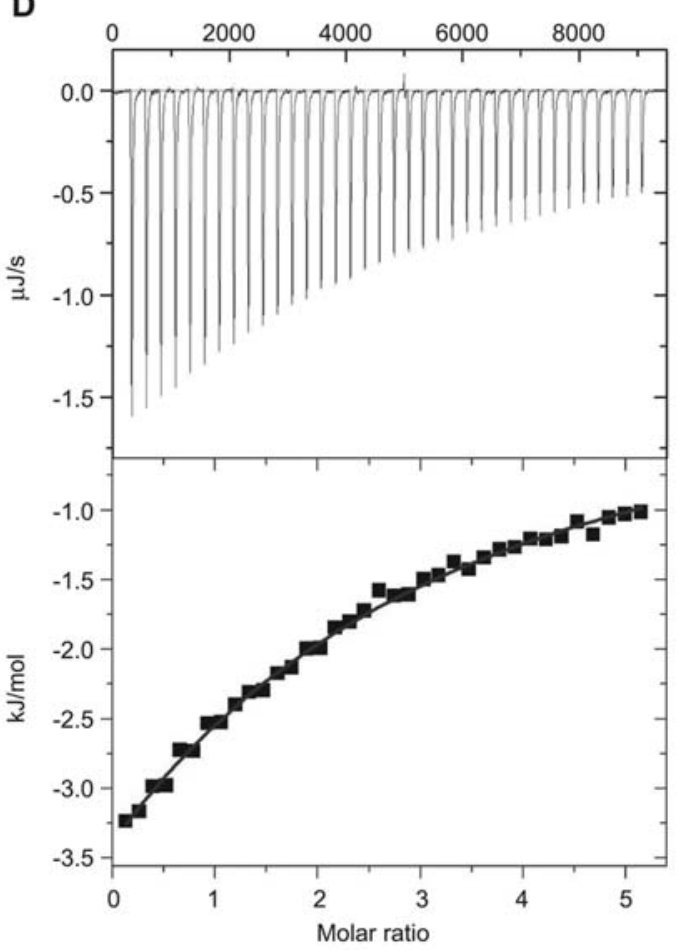

Figure 1 Overview of Hera and structure-sequence relationship of the N-terminal domain.

(A) The upper panel displays the Hera domain organization. The helicase core consists of two RecA-like domains and is followed by a dimerization and C-terminal RNA-binding domain. The lower panel highlights the conserved helicase motifs in the N-terminal RecA-like domain (RecA_N) with its secondary structure elements indicated below. The figure is drawn to scale. Numbers indicate domain boundaries and residue positions. (B) Comparison of the nucleotide specificity determinants in DEAD-box helicases (top) and several classes of GTPases (bottom). In these GTPases an aspartic acid contacts the exocyclic amino group and a ring nitrogen atom of guanine. Replacement by asparagine alters specificity to xanthine nucleotides. In DEAD-box proteins, the conserved glutamine residue selects adenine nucleotides via a bifurcated hydrogen bond donor of the side chain carboxamide to the N6 and N7 nitrogen atoms of the nucleobase. Mutation of this glutamine to glutamic acid removes the hydrogen bond donor. This hydrogen bond could be restored by use of 8-oxo-adenosine nucleotides, as these predominantly are in the oxo-tautomer in solution. (C) Unwinding of a 32/9mer RNA substrate derived from $23 \mathrm{~S}$ rRNA by wildtype Hera and the Q28E mutant. The upper band represents the fluorescently labeled double-stranded substrate and the lower band is the fluorescent single strand after unwinding (cartoons on right). No helicase activity is detected with Hera/8-oxo-ATP, Hera_Q28E/ATP or Hera_Q28E/8-oxo-ATP, whereas Hera/ATP unwinds this substrate. (D) Determination of 8-oxo-adenosine affinity for TthDEAD_Q28E by ITC. Evaluation of the data based on a single binding site yields $K_{\mathrm{a}}=1728 \pm 41.7 \mathrm{M}\left(K_{\mathrm{d}}=579 \mu \mathrm{M}\right), \Delta \mathrm{H}=-26.3 \pm 0.4 \mathrm{~kJ} / \mathrm{mol}$ and calculated $T \Delta S=-7.8 \mathrm{~kJ} / \mathrm{mol}$ for 8-oxo-adenosine. Measurements for 8-oxo-nucleotides were not performed due to scarcity of material and multiple binding modes for 8-oxo-AMP and 8-oxo-ADP for TthDEAD_Q28E as determined from the crystal structures.

possible way to probe the Q-motif for communication with the P-loop would be to alter the nucleotide specificity of the helicase while keeping spatial requirements and similar hydrogen bonding potential around the nucleotide binding site. For several classes of GTP-binding proteins, a strategy was devised where an aspartate to asparagine mutation shifted nucleotide specificity from guanine to xanthine (Figure 1B). Examples include H-Ras (Zhong et al., 1995), EF-Tu 
(Hwang and Miller, 1987; Weijland et al., 1993), Ypt1 (Jones et al., 1995), Rab-5 (Hoffenberg et al., 1995; Rybin et al., 1996), FtsY (Powers and Walter, 1995), adenylosuccinate synthetase (Kang et al., 1994) and Go $\alpha$ (although here a second mutation was essential for shifting nucleotide specificity) (Yu et al., 1997). Xanthine nucleotides are only transiently produced during purine metabolism and are not populated as triphosphates in vivo, allowing for separation of the signaling effect of a specific GTPase in the background of other GTPases. A similar reasoning as for GTPbinding proteins would allow, for instance, 8-oxo-adenine nucleotides to bind to a helicase where the conserved glutamine of the Q-motif is mutated to glutamate and also allow for selectively activating the helicase with altered specificity in vivo. Using the T. thermophilus RNA helicase Hera as a model, the Q28E mutation was introduced in both authentic Hera (Hera_Q28E) and the N-terminal RecA-like domain (TthDEAD_Q28E). Although the 8-oxo-adenine base did bind to TthDEAD_Q28E, the mutation in Hera rendered the helicase functionally inactive. Crystal structures for several nucleotide complexes revealed the expected hydrogen bonding mode for the 8-oxo-adenine nucleobase but conveyed interesting structural changes with respect to binding of the ribose and phosphate parts compared to the TthDEAD/AMP structure. The structures of TthDEAD_Q28E provide the molecular basis for the role of the conserved glutamine in the Q-motif in communication of the P-loop with the DEAD and SAT motifs and explain the loss of helicase activity in Hera_Q28E.

\section{Results}

8-Oxo-adenosine and the nucleotide triphosphate (8-oxoATP) were synthesized and the expected tautomeric form (Figure 1B) was confirmed by NMR analysis, in line with previous results on 8-oxo-adenine derivatives (Chatgilialoglu et al., 2006). 8-Oxo-ATP was tested as an energy source for Hera helicase activity (Figure 1C). Although wild-type Hera displayed ATP-dependent RNA unwinding activity on a 32/ 9mer RNA substrate derived from 23S rRNA (Linden et al., 2008), no unwinding of RNA in the presence of 8-oxo-ATP was observed. By contrast, Hera_Q28E showed no unwinding activity, neither with ATP nor with 8-oxo-ATP as the energy source (Figure 1C). These results indicate that the stereochemically rather conservative mutation Q28E strongly impacts helicase activity. Isothermal titration calorimetry of 8-oxo-adenosine as a probe for base- and ribose-mediated binding to TthDEAD_Q28E yielded a reaction enthalpy $\Delta \mathrm{H}=-26.3 \pm 0.4 \mathrm{~kJ} / \mathrm{mol}$ and a dissociation constant $K_{\mathrm{d}}=$ $579 \mu \mathrm{M}$ (Figure 1D). ATP affinities of DEAD-box proteins typically range between $80 \mu \mathrm{M}$ to $>1 \mathrm{mM}$ (Cordin et al., 2006). For Hera, nucleotide affinities for ATP analogs are $\sim 200 \mu \mathrm{M}$ (M.H. Linden and D. Klostermeier, unpublished data). For the TthDEAD/AMP complex, we previously determined a $K_{\mathrm{d}}=246 \mu \mathrm{M}$. The AMP co-crystal structure shows several interactions of the phosphate moiety with the P-loop (Rudolph et al., 2006), indicating a substantial ener- getic contribution to binding. Thus, a mere twofold reduction $(\Delta \Delta \mathrm{G}=1.7 \mathrm{~kJ} / \mathrm{mol}$ at $298 \mathrm{~K})$ in affinity for the TthDEAD_Q28E/8-oxo-adenosine complex points toward specific binding of the modified nucleobase 8-oxo-adenine to the mutated Q-motif. Owing to lack of material, no detailed binding studies were possible with 8-oxo-adenosine nucleotides.

To rationalize the effect of the Q28E mutation on the RNA helicase activity of Hera and to define the binding mode of 8-oxo-adenosine and derived nucleotides, we determined crystal structures of unliganded TthDEAD_Q28E and its complexes with 8-oxo-adenosine, 8-oxo-AMP and 8-oxoADP in several crystal forms. The Hera/nucleotide complexes were obtained in situ by limited hydrolysis of 8-oxo-ATP during the crystallization process. The structures were determined by molecular replacement using the previously determined dimeric TthDEAD structure as the search model (PDB-ID 2gxs) (Rudolph et al., 2006). The models were refined to resolutions of 1.4-2.6 $\AA$ (Table 1).

\section{Overall structure of TthDEAD}

The structure of TthDEAD_Q28E displays all salient features of a DEAD-box domain resembling a RecA-fold (Story and Steitz, 1992; Story et al., 1992): a central seven-stranded parallel $\beta$-sheet that is flanked by five and four $\alpha$-helices on either side (Figure 2A). Compared to the canonical RecA fold, the DEAD domain possesses an N-terminal extension of approximately 25 residues that contain the Q-motif (see below) and cap the nucleotide binding domain. In all three crystal forms discussed here, TthDEAD_Q28E forms dimers of the same kind as the wild-type TthDEAD. The prominent feature is a 14-stranded intermolecular $\beta$-sheet in a top-down fashion (Figure 2B). Superposition of the first monomer of the six dimeric TthDEAD_Q28E structures (two dimers are present in triclinic form II) onto the first monomer of the dimeric TthDEAD (PDB-ID 2gxs) structure yields a root mean square deviation (rmsd) of $<1.3 \AA$ over all $\mathrm{C} \alpha$ atoms. Based on this superposition, structural plasticity for the second monomer is apparent with displacements of up to $5.2 \AA$ and rotation up to $8.4^{\circ}$. The variability within the dimers is most prominent when the wild-type TthDEAD/AMP and TthDEAD_Q28E/8-oxo-ADP structures are compared (see below). Although there is no indication for dimerization of either wild-type or TthDEAD_Q28E in solution, this dimer has now been observed in four independent crystal settings and appears to be a low energy state that is populated at least at high concentrations of TthDEAD. Full-length Hera is indeed a stable dimer but here dimerization is achieved by a dedicated dimerization domain outside the helicase core that is currently unique to Hera (Klostermeier and Rudolph, 2009).

\section{Effect of the Q28E mutation on the structure of TthDEAD}

In the structure of TthDEAD with orthophosphate bound (no apo-structure is available for the wild-type) the carboxamide side chain of Gln28 forms four hydrogen bonds: two with 


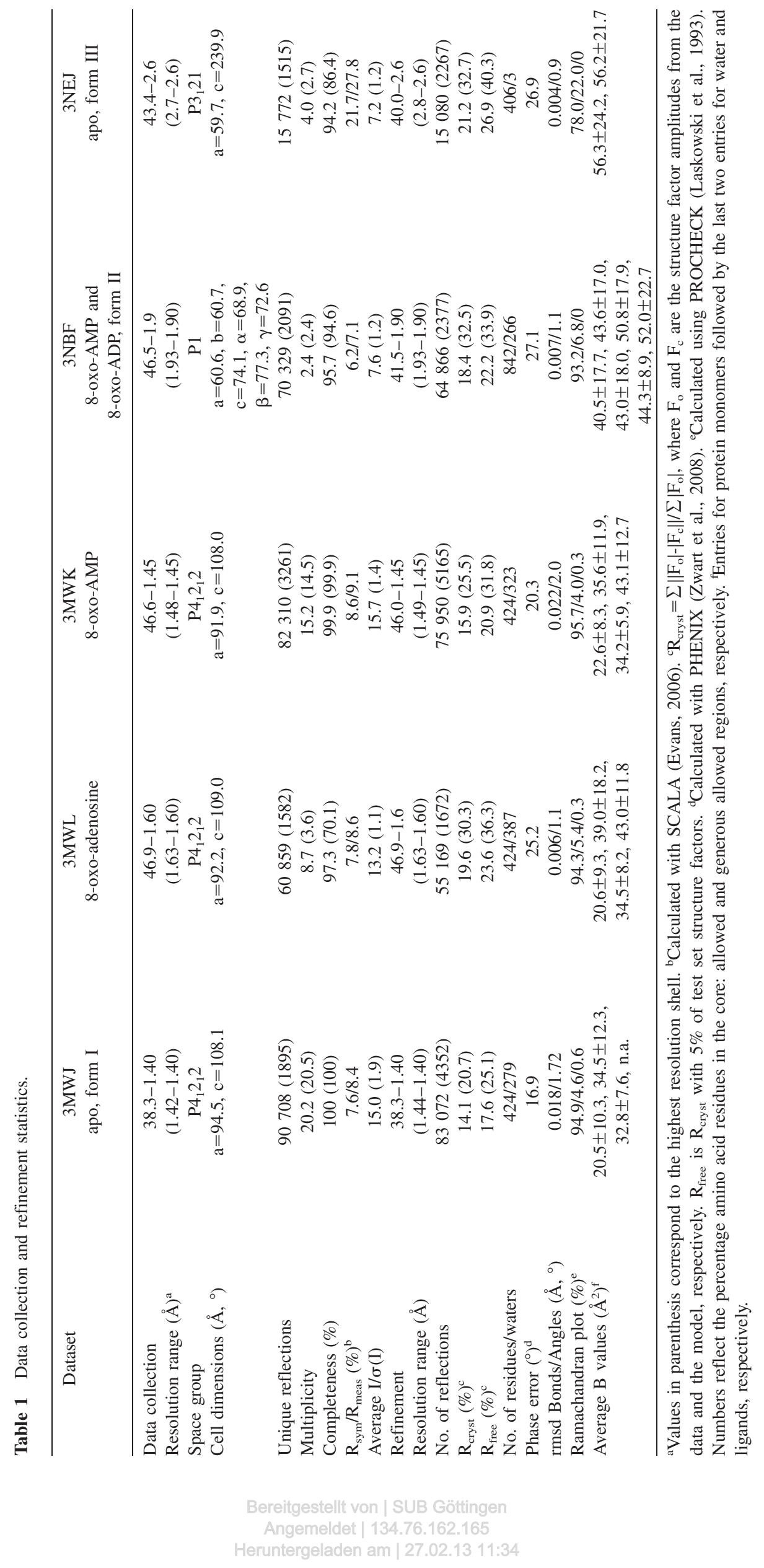



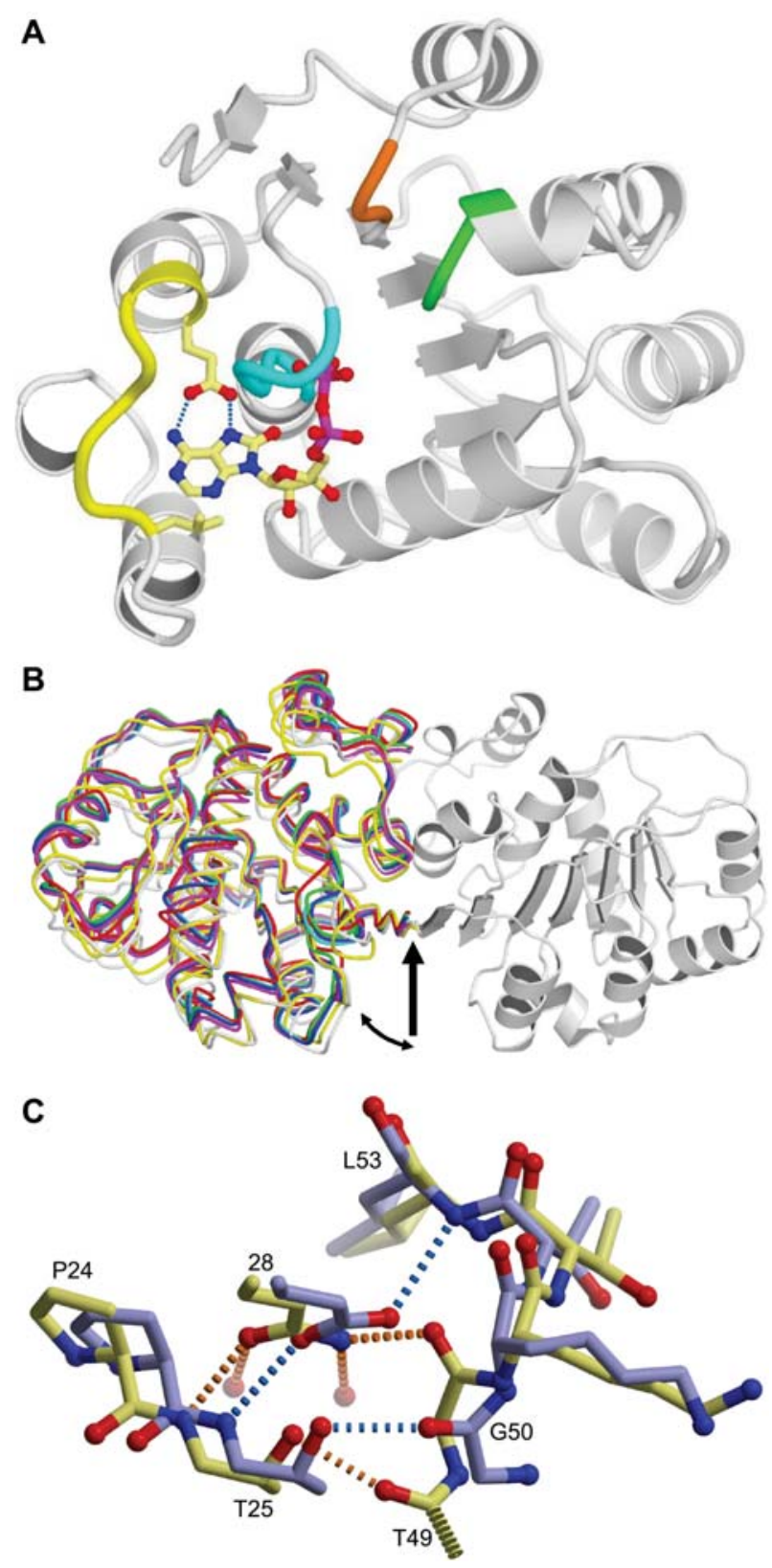

Figure 2 Salient features of the ThDEAD_Q28E structures. (A) Overview of the ThDEAD_Q28E monomer. The mutated Qmotif Q28E, the hydrophobic residue upstream of the Q-motif (Leu21) and 8-oxo-ADP are shown as yellow stick models. The two key hydrogen bonds from Glu28 to 8-oxo-adenine are drawn as blue dashed lines. The P-loop is marked in cyan, the DEAD-box in green and the SAT motif in orange. (B) The TthDEAD dimer as present in the crystal structures is mediated by an intermolecular $\beta$-sheet. The dimers are superimposed on one monomer of the TthDEAD/ AMP complex (PDB-ID 2gxs, gray on right side). The second monomers are drawn as backbone traces and are colored as follows: TthDEAD/AMP in gray, TthDEAD_Q28E apo form I in green, TthDEAD_Q28E apo form III in red, TthDEAD_Q28E/8-oxo-adenosine in blue, TthDEAD_Q28E/8-oxo-AMP in cyan and the two dimers of TthDEAD_Q28E/8-oxo-ADP of crystal form II are colored in yellow and magenta. Domain movements are apparent, hinging about the center of the $\beta$-sheet (arrow). (C) Effect of the Q28E mutation on the local structure of TthDEAD. Wild-type and mutant are colored yellow and blue, respectively. water molecules and two with protein atoms (Figure 2C). The Gln28 side chain carbonyl group hydrogen bonds to the main chain amide of the Q-motif residue Thr25 and the $\mathrm{NH}_{2}$ group of Gln28 contacts the main chain carbonyl of the Ploop residue Gly50, thus effectively connecting the Q-motif and the P-loop. The apo-TthDEAD_Q28E structure reveals several consequences of the Gln28Glu mutation. First, no water molecules are present. Second, the hydrogen bond to Gly50 is disrupted due to opposition of two hydrogen bond acceptors. Gly50 and adjoining residues of the P-loop move away from their position in the TthDEAD structure by up to $2.6 \AA$. This shift could be induced by electrostatic repulsion from Glu28 that is likely deprotonated under the $\mathrm{pH}$ values of crystallization (7.5-9.0). Third, the movement of the Ploop and a shift of Glu28 relative to Gln28 enable a novel hydrogen bond between the amide nitrogen of Leu53 and Glu28. Interestingly, a hydrogen bond between the side chain of Thr25 in the Q-motif and the P-loop is retained in both cases. Although in the wild-type the carbonyl group of Thr49 accepts this hydrogen bond, this role is served by Gly50 due to its rotation in the Gln28E mutation (Figure 2C). Thus, already in the absence of nucleotides there are significant changes of the apo-structures in wild-type and Q28E TthDEAD, which impact on the communication between helicase motifs.

\section{Unusual nucleotide binding to TthDEAD_Q28E}

Apart from Hera, several crystal structures of DEAD-box proteins in complex with AMP are now known including DDX3X (Högbom et al., 2007), eIF4A (Schütz et al., 2008), DDX53 (PDB-ID 3iuy, unpublished) and DDX47 (PDB-ID 3ber, unpublished). Super-positions of these complexes reveal virtually identical conformations for the AMP ligand and the P-loop (binding site shown for Hera in Figure 3A). In all structures, the adenine base binds to the conserved glutamine side chain of the Q-motif (Q28 in Hera). In most DEAD-box proteins, an aromatic side chain located approximately seven residues upstream of the glutamine stacks onto the nucleotide base. In $88 \%$ from a set 277 sequences, this residue is a phenylalanine (Tanner et al., 2003). In other cases, the aromatic side chain can be replaced by aliphatic residues such as L21 in Hera or an isoleucine in DDX53. In Hera, Q28 and T25 of the Q-motif form hydrogen bonds with the main chain carbonyl groups of P-loop residues G50 and T49, respectively. The phosphate moiety of the nucleotide is bound in a canonic fashion by main chain amide nitrogen atoms of T47, T49, and G50 of the P-loop (Figure 3A). Interactions between the Q-motif, the nucleotide and the Ploop establish a three-dimensional network that is primed for sensing the type and phosphorylation state of the nucleotide.

\section{Binding of 8-oxo-adenosine and 8-oxo-AMP}

As anticipated, the nucleotide base of 8-oxo-adenine binds to the side chain of Glu28 via a bidentate hydrogen bond. Analogous to the wild-type situation, a third hydrogen bond is formed by the exocyclic amino group with the carbonyl group of Thr23 (Figure 3B). The oxo-group in 8-oxo-adenine 

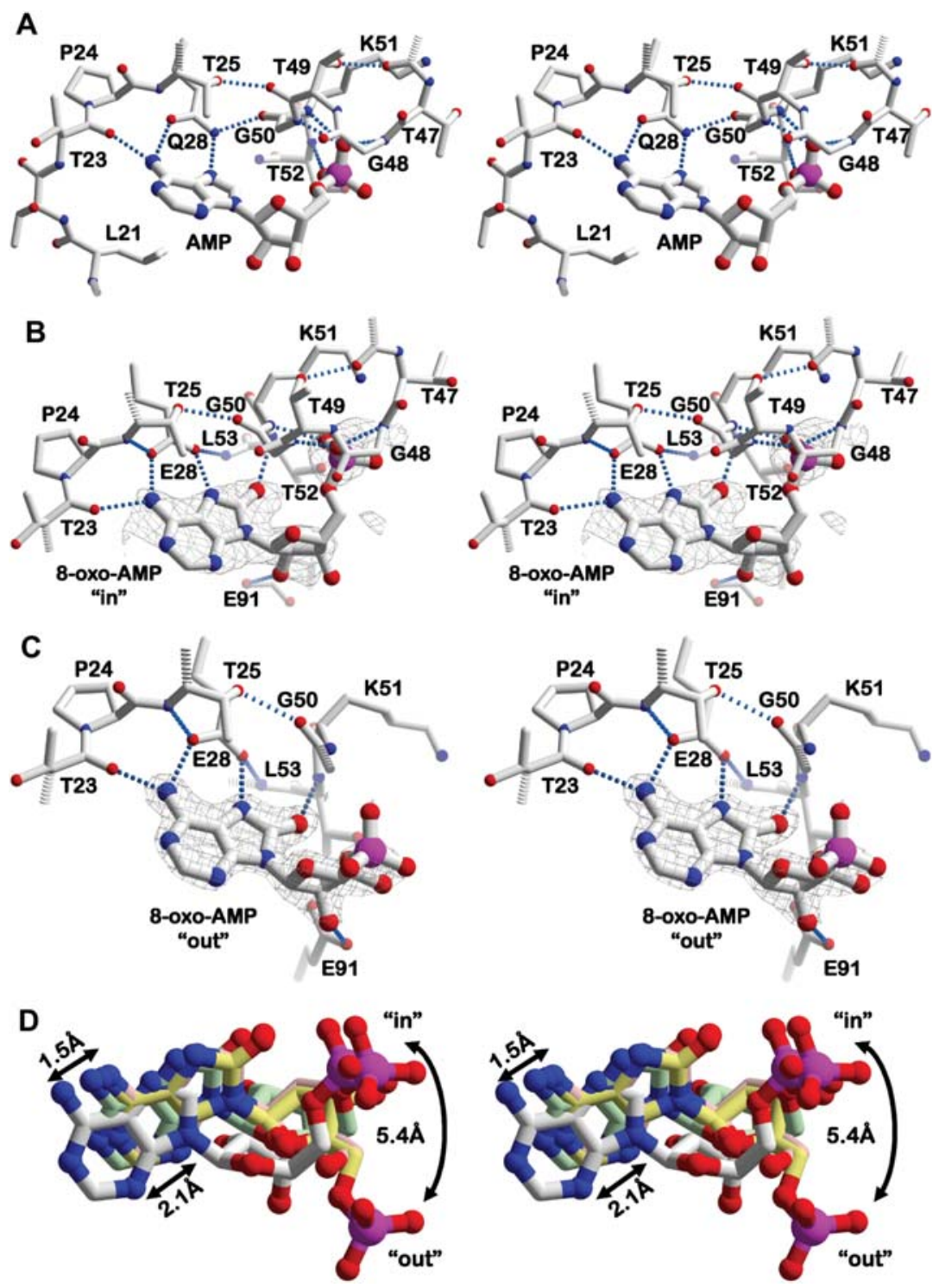

Figure 3 Details of nucleotide monophosphate binding to TthDEAD and the Q28E mutant.

(A) Stereo-view of the hydrogen bond network in the AMP structure (PDB-ID 2gxs) for comparison. (B) Stereo-view of the hydrogen bond network around 8-oxo-AMP with the monophosphate moiety bound to the P-loop (PDB-ID 3nbf). (C) Stereo-view of the hydrogen bond network in another 8-oxo-AMP complex (PDB-ID 3mwk). The phosphate part does not bind to the P-loop in this structure. Its flexibility is indicated by a deteriorating electron density compared to the nucleobase. Note the retention of the dual hydrogen bonds between the nucleobases and E28 in (B) and (C) when compared to the wild-type Q28 in (A) and the shifts of the P-loops. Omit map electron densities

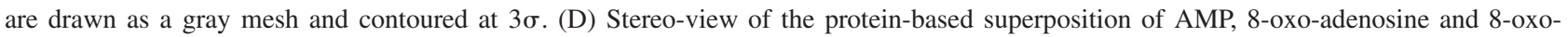
AMP ligands. Carbon atoms of AMP are colored in light gray, those of 8-oxo-adenosine are drawn in rose and carbon atoms of the in- and out-conformations of 8-oxo-AMP are shown in green and yellow, respectively. 8-Oxo-adenosine (hydrogen bond network not shown) superimposes very closely with 8-oxo-AMP. The nucleobases of the 8-oxo-compounds have shifted significantly compared to adenine. The ribose-phosphate part of 8-oxo-AMP has rotated about the glycosidic bond, placing the phosphate of 8-oxo-AMP $5.4 \AA$ away from its position in the AMP structure.

forms an additional hydrogen bond to the backbone amide group of Gly50, which is possible due to a rotation of the Lys51-Thr52 peptide plane. This binding pattern for the 8oxo-adenine base is universal for all 8-oxo-adenosine nucleotide complexes described here. In the 8-oxo-AMP complex, there are two binding modes for the ribose-phosphate part of 8-oxo-AMP, termed in and out. The in-conformation (Figure $3 \mathrm{~B}$ ) corresponds to the classic localization of the phosphate moiety in the P-loop where negative charge(s) are neutralized by contacts with the side chain of Lys51, hydrogen bonds to the main chain amides of P-loop residues and the macro dipole of the $\alpha$-helix C-terminal to the P-loop (Figure 1A). By contrast, the out-conformation (Figure 3C) represents a non-productive situation where the phosphate moiety does not bind to the P-loop but is oriented towards bulk solvent and appears rather flexible, as judged from weak electron 

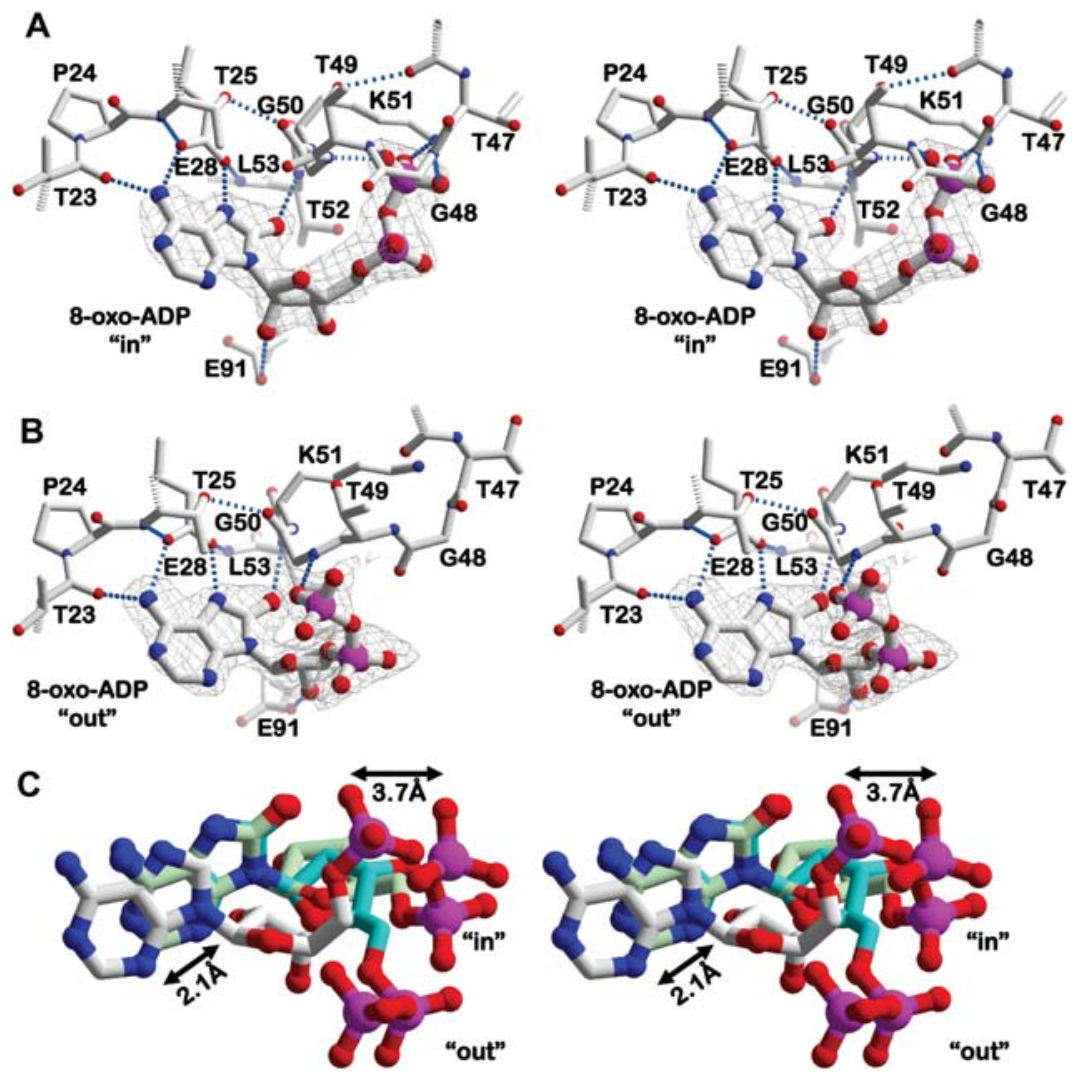

Figure 4 Details of 8-oxo-ADP binding to the TthDEAD_Q28E mutant.

(A) Stereo-view of the hydrogen bond network formed by 8-oxo-ADP in the P-loop bound in-conformation. (B) Corresponding view of the out-conformation not bound to the P-loop. (C) Protein-based superposition of AMP and 8-oxo-ADP. The two conformations of 8-oxo-ADP, shown in green and cyan, differ with respect to the position of their phosphate parts. The nucleobases are shifted to a similar magnitude as observed for 8-oxo-AMP (Figure 3). The terminal phosphates of AMP in wild-type TthDEAD and 8-oxo-ADP in the in-conformation are $3.7 \AA$ apart, despite similar interactions with the P-loop.

density. The presence of such a conformation indicates that binding of the phosphate part in 8-oxo-AMP to the P-loop may not be as energetically favorable as for the adenine nucleotides. Superposition of the proteins in the two monophosphate complexes reveals that the out-conformation is realized by rotations about the glycosidic and the sugar C4$\mathrm{C} 5$ bonds, in sum leading to a displacement of the phosphate moiety by $5.4 \AA$ (Figure 3D). A possible explanation for the presence of the out-conformation is apparent by comparing the placement of the nucleobases within the active site: the additional oxygen atom in 8-oxo-adenine seems to push and tilt the nucleobase away from the P-loop by $1.5-2.1 \AA$. A concomitant pull on the sugar-phosphate moiety may explain a loss in affinity for the P-loop, such that both conformations can be trapped in crystal structures.

\section{Binding of 8-oxo-ADP}

The 8-oxo-adenine base in the 8-oxo-ADP complex establishes exactly the same interactions to TthDEAD_Q28E as described above for 8-oxo-adenosine and 8-oxo-AMP (Figure 4). In addition, the two in- and out-conformations of the ribose-phosphate moiety are also realized in the 8-oxo-ADP/ TthDEAD_Q28E complexes. Both conformations are well defined by electron density and display different conformations of the ribose-phosphate parts when bound inside and outside the P-loop, respectively. In the in-conformation, the $\beta$-phosphate, which entertains four direct hydrogen bonds to amide nitrogen atoms of the P-loop, is placed at approximately the same location as the $\alpha$-phosphate in the 8-oxoAMP complex (compare Figures $2 \mathrm{~B}$ and $3 \mathrm{~A}$ ). Compared to the wild-type TthDEAD/AMP complex, the $\beta$-phosphate of 8-oxo-ADP is located approximately $3.7 \AA$ from the position of the $\alpha$-phosphate in AMP (Figure 4C). Apart from crystal contacts (not shown), the artificial out-conformation (Figure 4B) is stabilized by a single hydrogen bond of the $\beta$-phosphate to the amide nitrogen atom of the Thr49-Gly50 peptide bond, which is flipped compared to the in-conformation. Based on the comparisons between the 8-oxo-nucleotide/ TthDEAD_Q28E complexes, it can be concluded that the Ploop exhibits considerable plasticity, both in the absence and presence of non-natural nucleotides.

\section{Communication of helicase motifs in the nucleotide-binding domain}

Crystal structures of DEAD-box helicases in complex with ADP are available from DDX5 (PDB-ID 3fe2), DDX10 

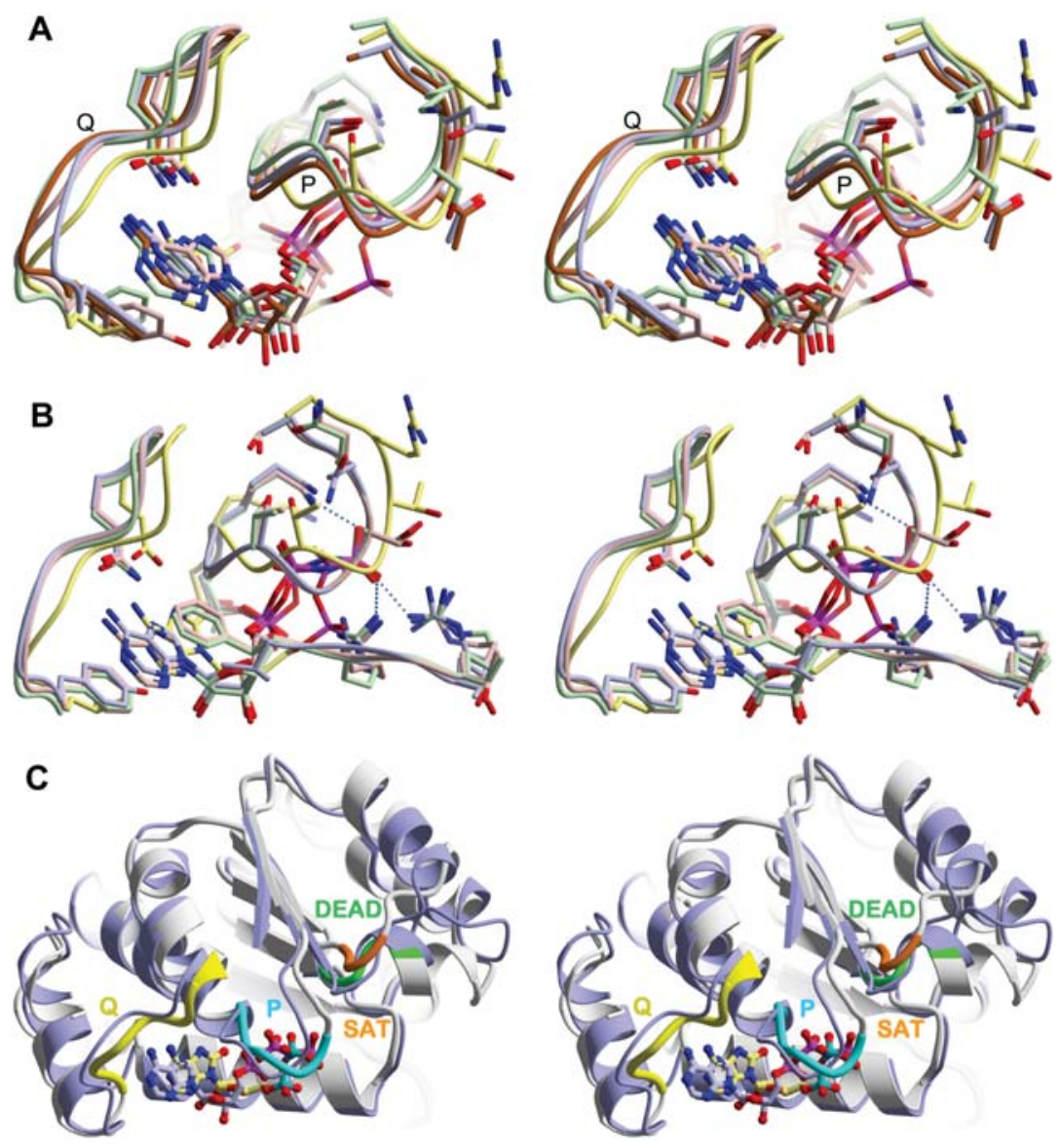

Figure 5 Communication of helicase motifs within the N-terminal Rec_A-like domain.

(A) Close-up stereo-view of the superposition of ADP-bound DEAD-box helicases DDX5 (PDB-ID 3fe2, blue), DDX10 (PDB-ID 2p13, pink), DDX20 (PDB-ID 2oxc, green) and DDX52 (PDB-ID 3dkp, brown) with TthDEAD_Q28E in complex with 8-oxo-ADP (in-conformation, yellow). For the ADP-complexes, the conformations of the Q-motif (labeled Q) vary considerably but the conformations of the Ploops (labeled P) are quite similar. The conformations of these motifs in TthDEAD_Q28E are very different from those of the ADP-complexes. (B) Close-up stereo-view of the superposition of RNA/ADPNP complexes of Vasa (PDB-ID 2db3, light blue), DBP5 (PDB-ID 3fht, green), DDX19 (PDB-ID 3g0h, pink) with TthDEAD_Q28E in complex with 8-oxo-ADP (in-conformation, yellow). The conformations of the Q-motif and the P-loops in these RNA complexes are very similar but again differ from the conformation in TthDEAD_Q28E. (C) Stereo-view of a superposition of the RecA_N domains of TthDEAD_Q28E in complex with 8-oxo-ADP (in-conformation grey) and the Drosophila melanogaster Vasa/RNA/ADPNP complex (light blue). Although the main body of the domains remains constant, there are concerted movements of the Q-motif, the nucleotide, the P-loop, the DEAD-box and the SAT motif when the structures are compared to each other.

(PDB-ID 2p13), DDX19 (PDB-ID 3ews), DDX20 (PDB-ID 2oxc) and DDX52 (PDB-ID 3dkp), which are all unpublished, except for DDX19 (Collins et al., 2009). Superposition of these complexes with the TthDEAD_Q28E/8-oxo-ADP structure reveals that the Q-motif exhibits structural plasticity, with the Q28E-complex marking one extreme (Figure 5A). Interestingly, in all ADP-complexes the P-loops adopt a very similar conformation that is again different from the TthDEAD_Q28E/8-oxo-ADP structure. The $\beta$-phosphate of 8-oxo-ADP occupies a different position in the P-loop compared to ADP, due to a different puckering of the ribose (see below).

To estimate how strong the P-loop conformation in 8-oxonucleotide complexes deviates from the active conformation in a closed RNA- and ATP-bound helicase, a structural comparison with the RNA complexes of Vasa (Sengoku et al.,
2006), DDX19 (Collins et al., 2009) and DBP5 (von Moeller et al., 2009) was performed (Figure 5B). Both the P-loop and the Q-motif in all three independent RNA/helicase structures have very similar conformations down to the level of side chain conformations, which contrasts the situation in the ADP-complexes. However, the Q-motif conformations markedly differ from the TthDEAD_Q28E/8-oxo-ADP complex (Figure 5B). Within the different 8-oxo-nucleotide complexes, there is also substantial P-loop plasticity (Figures 2 and 3). The Q28E mutation may increase the P-loop flexibility independent of the bound nucleotide and lead to a non-productive placement of the phosphate moiety in the P-loop. For example, the conformation of the ribose at the C5'-position is different for 8-oxo-ADP compared to ADP and the ATP analog ADPNP, placing the $\beta$-phosphate of 8-oxo-ADP at a position between the $\beta$ - and $\gamma$-phosphate of ADPNP (Figure 
5B). In addition, 8-oxo-adenine nucleotide binding to TthDEAD_Q28E has structural consequences that extend beyond the P-loop (Figure 5C). In nucleotide-free and apostructures of DEAD-box proteins, Lys51 (T.th. numbering) connects the P-loop to Glu152 of the DEAD-box via a salt bridge, and DEAD-box residue Asp154 links to Ser182 and Thr184 of the SAT motif. Binding of ADP/ $\mathrm{Mg}^{2+}$ or ATP/ $\mathrm{Mg}^{2+}$ disrupts the Lys51-Glu152 salt bridge and $\mathrm{Mg}^{2+}$ now connects the $\beta$-phosphate with Glu152 (Shi et al., 2004), which keeps the interaction between the motifs intact. In the 8-oxo-ADP complex, the connection of the P-loop and the DEAD-box is still in the ground state, with Lys51 electrostatically contacting Asp151 and Glu152 of the DEAD-box, probably because no $\mathrm{Mg}^{2+}$ is bound in this structure. Comparison of the three closed helicase structures Vasa, DDX19 and DBP5 shows that their DEAD and SAT motifs share virtually identical conformations, but again they differ from the 8-oxo-ADP structure. Likewise, among the 8-oxo-nucleotide complexes, the conformations of the DEAD and SAT motifs are very similar. In the SAT motif, the main differences between the closed conformations and the Hera_Q28E/ 8-oxo-nucleotide complexes are a shift of the conserved threonine by $3.3 \AA$ (C $\alpha$-distance to Vasa) and a flip of the Ala-Thr peptide plane. Taken together, these observations indicate that the Q28E mutation and/or the bound 8-oxonucleotides prevent establishment of the hydrogen bonding network between the P-loop and the SAT motif and thus abolish the RNA unwinding activity of Hera_Q28E.

\section{Discussion}

In this study, the role of the conserved glutamine residue in the Q-motif of the DEAD-box helicase Hera for nucleotide specificity and communication with the P-loop was probed by mutation to glutamic acid and adjustment of the nucleobase from adenine to 8-oxo-adenine. Upon changing the hydrogen bonding pattern of both the Q-motif residue 28 and the nucleobase, the double hydrogen bond between the glutamine of the Q-motif and the nucleobase was retained. This approach was successful with respect to maintaining specificity, but failed to keep a native interaction between the Qmotif and the P-loop. Consequently, no helicase activity of full-length Hera_Q28E with 8-oxo-ATP as energy source was observed.

A similar approach of mutating a conserved asparagine residue to aspartic acid in GTP-binding proteins has successfully changed specificity from guanine to xanthine nucleotides in various examples. The question arises as to why this approach was successful and, in addition to changing the nucleotide specificity, the XTPase and effector binding activity was also retained. The situation in GTP-binding proteins is rather simple: the asparagine/aspartate contacts only the nucleotide but no other protein parts. The xanthine atoms that differ from guanine point into the solvent, which can explain why signaling functionality of the XTPases is retained. By contrast, crystal structure analyses of TthDEAD_Q28E/8-oxo-nucleotide complexes provide two main explanations as to why helicase function is lost when the analogous glutamine-to-glutamate mutation is introduced: First, the Q-motif engages in interactions with the adenine base and also with the P-loop contacting the phosphate moiety of the bound nucleotide. The Q28E mutation opposes two hydrogen bond acceptors, E28 (Q-motif) and G50 (Ploop), which leads to a shift of the P-loop that could prompt all other conformational changes observed in the DEAD and SAT motives. Second, the introduction of an oxygen atom at the $\mathrm{C} 8$ position of adenine was essential to reverse the hydrogen bonding potential of N7 from acceptor to donor. This additional oxygen atom is small enough to retain the anti-conformation of the nucleobase in nucleotides but introduces another hydrogen bond acceptor that interacts with a main chain amide nitrogen of the P-loop. Thus, two additional P-loop interactions, one from the Q-motif and another from the nucleotide, are present in the Q28E/8-oxo system that may be responsible for disrupting the communication between helicase motifs.

Mutational analyses of the conserved glutamine residue in the Q-motif of DEAD-box proteins has been performed previously with the yeast translation-initiation factors eIF4A (Q48; Tanner et al., 2003) and Ded1 (Q169; Cordin et al., 2004). Mutation of these glutamine residues to either glutamate or alanine displayed lethal phenotypes in yeast. Surprisingly, ATP and ADP binding to the mutants was still observed in UV-crosslinking and ATPase competition experiments (Tanner et al., 2003), but ATPase activities were reduced significantly (Cordin et al., 2004), paralleled by little or no RNA unwinding. From these studies, a differential effect of the mutations on ADP and ATP binding was inferred with different determinants for binding of the two nucleotides, and the Q-motif was postulated as a molecular 'on/off switch'. The growth phenotypes and lacking helicase activities of the eIF4A and Ded1p Q-mutants are in line with the central role of the Q-motif glutamine for sensing the nucleotide state of the DEAD-box protein.

The structure of TthDEAD_Q28E demonstrates that mutants with a glutamic acid instead of the essential glutamine residue will not tolerate an adenine base, and we did not detect binding of Hera_Q28E to mantADP (data not shown). However, a secondary nucleotide binding site close to the RNA-binding site is observed in the TthDEAD_Q28E/ 8-oxo-ADP crystal structure (data not shown) and a pyrophosphate was observed in the same region of DDX52 (unpublished). Possibly, these secondary sites could contribute to the residual nucleotide binding as reported for eIF4A and Ded1p. Taken together, the structural and mutational data thus suggest that the conserved glutamine of the Q-motif plays a crucial role in adenine recognition and signal relay to the P-loop for unwinding activity. By contrast, structural data do not support a role of the Q-motif as a 'switch' that recognizes the phosphorylation state of bound nucleotide(s) as it only interacts with the nucleobase.

A significant number of DEAD-box proteins have been structurally characterized in complex with adenine nucleotides, ranging from ATP analogs to ADP and AMP. Since the determination of the TthDEAD/AMP complex structure, 
three more AMP complexes have been determined with DDX53, DDX47 (Schutz et al., 2010) and DDX3X (Högbom et al., 2007). The binding of AMP to helicases is not functionally relevant, but it is mechanistically interesting as it points to the nucleobase as the key for nucleotide affinity. By contrast, binding of the phosphates seems energetically neutral. This notion is corroborated by equilibrium dissociation constants for the TthDEAD/AMP (Rudolph et al., 2006) and TthDEAD_Q28E/8-oxo-adenosine complexes (this work) in the high micromolar range, similar to those reported for ADP and ATP analogs in a number of other DEAD-box proteins (Cordin et al., 2006), including Hera (M.H. Linden and D. Klostermeier, unpublished). As the phosphate groups in nucleotides do not provide additional binding energy, it could be concluded that the energy from hydrogen bonds of the phosphate part to the P-loop is transformed into conformational changes of the DEAD and SAT motifs toward a closure of the helicase inter-domain cleft in the ATP state (Yao et al., 1997; Kim et al., 1998; Johnson and McKay, 1999; Caruthers et al., 2000; Linden et al., 2008). In TthDEAD_Q28E, the hydrogen bonding network connecting the Q-motif, the P-loop, the DEAD-box and the SAT motif is maintained and these motifs have shifted in a concerted fashion when compared to the structures of the DEAD-box proteins Vasa, DDX19 and DBP5 in complex with RNA and ADPNP (Sengoku et al., 2006; Collins et al., 2009; von Moeller et al., 2009). However, the abnormal Ploop conformation that is dictated by the mutated Q-motif leads to a displacement of the phosphate moiety of bound nucleotides, effectively abolishing the nucleotide-sensing capability of the P-loop. As a consequence, the relay of conformational changes that eventually leads to a closure of the cleft in the helicase core is blocked at the initial stage, abrogating unwinding activity.

\section{Materials and methods}

\section{Synthesis of 8-oxo-adenosine and derived nucleotides}

All reagents were of analytical grade and used without further purification. Solvents were of the highest grade available. Dry solvents were stored over molecular sieves ( $4 \AA$ ). Glass equipment utilized for reactions under inert atmosphere was flame dried before use. ${ }^{1} \mathrm{H}$ - and ${ }^{13} \mathrm{C}$-NMR spectra were recorded with a Varian Unity 300 spectrometer, a Varian Inova 500 spectrometer or a Varian Inova 600 spectrometer. Chemical shifts are quoted in parts per million (ppm) downfield of tetramethylsilane. Abbreviations for multiplicities are: s, singlet; d, doublet; t, triplet; m, multiplet; br, broad. Coupling constants are given in Hz. Mass spectrometry was carried out using Finnigan LQC or TSQ 7000 instruments. HRMS spectra were measured with a Bruker APEX-Q IV 7T instrument. HPLC analysis was performed using a Pharmacia Äkta basic instrument (pump type P-900, variable wavelength detector) with different solvent systems. Compounds were analyzed using a JASCO ReproSil column ODS-A, $5 \mu \mathrm{m}$, RP-C18, $250 \times 4.6 \mathrm{~mm}$, with a flow rate of $1 \mathrm{ml} / \mathrm{min}$. Semi-preparative purification was performed using a JASCO ReproSil column ODS-A, RP-C18, $250 \times 10 \mathrm{~mm}$, with a flow rate of $3 \mathrm{ml} / \mathrm{min}$. The synthesis of 8 -oxo-adenosine and the nucle- oside-5'-triphosphate was essentially performed as described (Scheme 1; Chatgilialoglu et al., 2006).

\section{8-Bromo-adenosine (2)}

An aqueous solution of sodium acetate $(0.5 \mathrm{M}, 100 \mathrm{ml})$ was treated with acetic acid until $\mathrm{pH} 4.0$ was reached. Adenosine (1) (1.50 g, $5.61 \mathrm{mmol}$ ) was added to the buffer and stirred under gentle heating until the solid was completely dissolved. The solution was allowed to cool to room temperature and a solution of bromine (2.69 g, $16.8 \mathrm{mmol})$ in water $(50.0 \mathrm{ml})$ was added. The resulting reaction mixture was stirred at room temperature overnight. The solution was then decolorized by addition of solid sodium bisulfite and neutralized by addition of aqueous sodium hydroxide solution (50\%). The suspension was allowed to stand at $5^{\circ} \mathrm{C}$ overnight. The solid was then collected by filtration and the filter cake was washed with water $(3 \times 10.0 \mathrm{ml})$ and acetone $(1 \times 10.0 \mathrm{ml})$. The pure product was dried under vacuum to yield $1.41 \mathrm{~g}(4.08 \mathrm{mmol}, 73 \%) .{ }^{1} \mathrm{H}-\mathrm{NMR}$ $\left(300 \mathrm{MHz}, \mathrm{DMSO}-\mathrm{D}_{6}, 35^{\circ} \mathrm{C}\right): \delta=3.48-3.57\left(\mathrm{~m}, 1 \mathrm{H}, \mathrm{H} 5^{\prime}\right), 3.68(\mathrm{td}$, $\left.{ }^{2} J_{\mathrm{H}, \mathrm{H}}=12.1 \mathrm{~Hz},{ }^{3} J_{\mathrm{H}, \mathrm{H}}=3.9 \mathrm{~Hz}, 1 \mathrm{H}, \mathrm{H} 5^{\prime}\right), 3.99\left(\mathrm{dd},{ }^{3} J_{\mathrm{H}, \mathrm{H}}=6.4 \mathrm{~Hz}\right.$, $\left.{ }^{3} J_{\mathrm{H}, \mathrm{H}}=3.9 \mathrm{~Hz}, 1 \mathrm{H}, \mathrm{H} 4^{\prime}\right), 4.18-4.23\left(\mathrm{~m}, 1 \mathrm{H}, \mathrm{H} 3^{\prime}\right), 5.06-5.13(\mathrm{~m}$, $\left.1 \mathrm{H}, \mathrm{H} 2^{\prime}\right), 5.18\left(\mathrm{~d},{ }^{3} J_{\mathrm{H}, \mathrm{H}}=4.2 \mathrm{~Hz}, 1 \mathrm{H}, 3^{\prime}-\mathrm{OH}\right), 5.40-5.47(\mathrm{~m}, 2 \mathrm{H}$, $\left.2^{\prime}-\mathrm{OH}, 5^{\prime}-\mathrm{OH}\right), 5.84\left(\mathrm{~d},{ }^{3} J_{\mathrm{H}, \mathrm{H}}=6.8 \mathrm{~Hz}, 1 \mathrm{H}, \mathrm{H} 1^{\prime}\right), 7.51\left(\mathrm{~s}_{\mathrm{br}}, 1 \mathrm{H}\right.$, $\left.\mathrm{NH}_{2}\right), 8.12(\mathrm{~s}, 1 \mathrm{H}, \mathrm{H} 2) \mathrm{ppm} .{ }^{13} \mathrm{C}-\mathrm{NMR}(500 \mathrm{MHz}$, DMSO-D $\left.35^{\circ} \mathrm{C}\right): \delta=62.0\left(\mathrm{C}^{\prime}\right), 70.8\left(\mathrm{C}^{\prime}\right), 71.0\left(\mathrm{C} 2^{\prime}\right), 86.6\left(\mathrm{C}^{\prime}\right), 90.3\left(\mathrm{C}^{\prime}\right)$, 119.5 (C5), 126.9 (C8), 149.7 (C4), 152.2 (C2), 154.9 (C6) ppm. ESI-MS m/z (rel.\%): $346.0(100)[\mathrm{M}+\mathrm{H}]^{+}, 368.0(54)[\mathrm{M}+\mathrm{Na}]^{+}$. HRMS (ESI): 346.0139 (calculated for $\mathrm{C}_{10} \mathrm{H}_{13} \mathrm{BrN}_{5} \mathrm{O}_{4}$ : 346.0145), 367.9956 (calculated for $\mathrm{C}_{10} \mathrm{H}_{12} \mathrm{BrN}_{5} \mathrm{O}_{4} \mathrm{Na}$ : 367.9965 ).

\section{8-Oxo-adenosine (3)}

A solution of 8-bromo-adenosine (2) (346 mg, $1.00 \mathrm{mmol}$ ), 2-mercaptoethanol (234 mg, $210 \mu \mathrm{l}, 3.00 \mathrm{mmol}$ ) and triethylamine $(1.01 \mathrm{~g}, 1.39 \mathrm{ml}, 10.0 \mathrm{mmol})$ in water $(100 \mathrm{ml})$ was stirred under reflux for $4 \mathrm{~h}$. Afterwards, the solvent was removed under reduced pressure and the crude product was purified by semi-preparative HPLC. Yield: $254 \mathrm{mg}, 898 \mu \mathrm{mol}, 90 \% .{ }^{1} \mathrm{H}-\mathrm{NMR}\left(300 \mathrm{MHz}, \mathrm{D}_{2} \mathrm{O}\right.$, $\left.35^{\circ} \mathrm{C}\right): \delta=3.84\left(\mathrm{dd},{ }^{2} J_{\mathrm{H}, \mathrm{H}}=12.8 \mathrm{~Hz},{ }^{3} J_{\mathrm{H}, \mathrm{H}}=3.9 \mathrm{~Hz}, 1 \mathrm{H}, \mathrm{H} 5^{\prime}\right), 3.93$ $\left(\mathrm{dd},{ }^{2} J_{\mathrm{H}, \mathrm{H}}=12.7 \mathrm{~Hz},{ }^{3} J_{\mathrm{H}, \mathrm{H}}=2.8 \mathrm{~Hz}, 1 \mathrm{H}, \mathrm{H}^{\prime}\right), 4.25(\mathrm{dd}$, $\left.{ }^{3} J_{\mathrm{H}, \mathrm{H}}=6.6 \mathrm{~Hz},{ }^{3} J_{\mathrm{H}, \mathrm{H}}=3.2 \mathrm{~Hz}, 1 \mathrm{H}, \mathrm{H} 4^{\prime}\right), 4.48\left(\mathrm{dd},{ }^{3} J_{\mathrm{H}, \mathrm{H}}=5.5 \mathrm{~Hz}\right.$, $\left.{ }^{3} J_{\mathrm{H}, \mathrm{H}}=3.2 \mathrm{~Hz}, 1 \mathrm{H}, \mathrm{H}^{\prime}\right), 4.99\left(\mathrm{dd},{ }^{3} J_{\mathrm{H}, \mathrm{H}}=5.6 \mathrm{~Hz},{ }^{3} J_{\mathrm{H}, \mathrm{H}}=6.3 \mathrm{~Hz}\right.$, $\left.1 \mathrm{H}, \mathrm{H} 2^{\prime}\right), 5.90\left(\mathrm{~d},{ }^{3} \mathrm{~J}_{\mathrm{H}, \mathrm{H}}=6.5 \mathrm{~Hz}, 1 \mathrm{H}, \mathrm{H}^{\prime}\right), 8.04$ (s, $\left.1 \mathrm{H}, \mathrm{H} 2\right) \mathrm{ppm}$. ${ }^{13} \mathrm{C}-\mathrm{NMR}\left(300 \mathrm{MHz}, \mathrm{D}_{2} \mathrm{O}, 35^{\circ} \mathrm{C}\right): \delta=62.1\left(\mathrm{C}^{\prime}\right), 70.9\left(\mathrm{C}^{\prime}\right), 71.3$ $\left(\mathrm{C} 2^{\prime}\right), 85.5\left(\mathrm{C} 4^{\prime}\right), 86.2\left(\mathrm{Cl}^{\prime}\right), 104.4(\mathrm{C} 5), 146.2(\mathrm{C} 4), 147.5(\mathrm{C} 2)$, 151.0 (C8), 153.0 (C6) ppm. ESI-MS m/z (rel.\%): 282.1 (100) [M$\mathrm{H}^{-}$. HRMS (ESI): 282.0850 (calculated for $\mathrm{C}_{10} \mathrm{H}_{12} \mathrm{~N}_{5} \mathrm{O}_{5}: 282.0844$ ). Semi-preparative HPLC (RP-C18, 5-60\% B [A=MilliQ- $\mathrm{H}_{2} \mathrm{O}$, $\left.\mathrm{B}=\mathrm{MeCN}: \mathrm{H}_{2} \mathrm{O} 8: 2\right]$ in $30 \mathrm{~min}$ ): $11.21 \mathrm{~min}$.

\section{8-Oxo-adenosine-5'-triphosphate (4)}

A solution of 8-oxo-adenosine (3) $(42.5 \mathrm{mg}, 150 \mu \mathrm{mol})$ and proton sponge $(129 \mathrm{mg}, 602 \mu \mathrm{mol})$ in trimethyl phosphate $(2.00 \mathrm{ml})$ was stirred at room temperature for $0.5 \mathrm{~h}$. The solution was cooled to $0^{\circ} \mathrm{C}$ and phosphorous oxychloride $(25.2 \mathrm{mg}, 15.1 \mu \mathrm{l}, 165 \mu \mathrm{mol})$ was added drop-wise. The clear solution was then stirred at $0^{\circ} \mathrm{C}$ for $2 \mathrm{~h}$. A mixture of tributylamine $(111 \mathrm{mg}, 143 \mu \mathrm{l}, 600 \mu \mathrm{mol})$ and bis-tri- $n$-butylammonium pyrophosphate $(535 \mathrm{mg}, 975 \mu \mathrm{mol})$ in dry DMF $(750 \mu 1)$ was added in one portion. The reaction was allowed to stir at $0^{\circ} \mathrm{C}$ for $15 \mathrm{~min}$, and added drop-wise to cold TEAA buffer $(0.2 \mathrm{M}, 25.0 \mathrm{ml}, \mathrm{pH}=7)$. The solution was stored at $4^{\circ} \mathrm{C}$ overnight, washed with ethyl acetate $(4 \times 20.0 \mathrm{ml})$ and evaporated to dryness. The crude product was purified by analytical HPLC. Yield: $33.5 \mathrm{mg}$, 
<smiles></smiles>

1

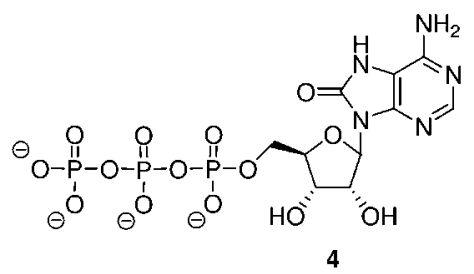

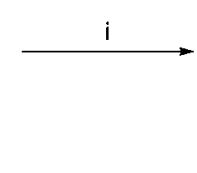

iii

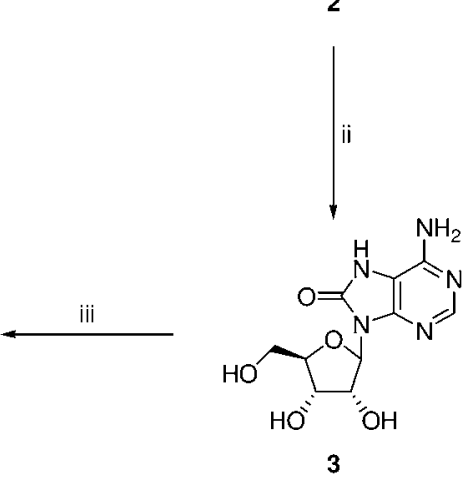

Scheme 1 Reaction scheme for the synthesis of 8-oxo-ATP.

(i) Bromine, acetate buffer $\mathrm{pH} 4$, room temperature (rt), overnight, 73\%. (ii) 2-Mercaptoethanol, $\mathrm{Et}_{3} \mathrm{~N}, \mathrm{H}_{2} \mathrm{O}, \mathrm{reflux}, 4 \mathrm{~h}, 90 \%$. (iii) [a] Trimethyl phosphate, proton sponge, rt, $0.5 \mathrm{~h}$. [b] $\mathrm{POCl}_{3}, 0^{\circ} \mathrm{C}, 2 \mathrm{~h}$. [c] bis-tri- $n$-butylammonium pyrophosphate, $\mathrm{Bu}_{3} \mathrm{~N}, \mathrm{DMF}^{\circ} 0^{\circ} \mathrm{C}, 15 \mathrm{~min}$. [d] $0.2 \mathrm{M}$ TEAA buffer $\mathrm{pH} 7.4,4^{\circ} \mathrm{C}, 22 \mathrm{~h}$.

$64.1 \mu \mathrm{mol}, 43 \%$. ${ }^{1} \mathrm{H}-\mathrm{NMR}\left(600 \mathrm{MHz}, \mathrm{D}_{2} \mathrm{O}, 35^{\circ} \mathrm{C}\right): \delta=4.18-4.23$ (m, $\left.1 \mathrm{H}, \mathrm{H} 5^{\prime}\right), 4.27-4.32$ (m, $\left.2 \mathrm{H}, \mathrm{H} 4^{\prime}, \mathrm{H} 5^{\prime}\right), 4.62-4.64(\mathrm{~m}, 1 \mathrm{H}$, $\left.\mathrm{H} 3^{\prime}\right), 5.25\left(\mathrm{t},{ }^{3} J_{\mathrm{H}, \mathrm{H}}=5.6 \mathrm{~Hz}, 1 \mathrm{H}, \mathrm{H} 2^{\prime}\right), 5.94\left(\mathrm{~d},{ }^{3} \mathrm{~J}_{\mathrm{H}, \mathrm{H}}=5.4 \mathrm{~Hz}, 1 \mathrm{H}\right.$, $\left.\mathrm{H} 1^{\prime}\right), 8.21$ (s, $\left.1 \mathrm{H}, \mathrm{H} 2\right)$ ppm. ${ }^{13} \mathrm{C}-\mathrm{NMR}\left(500 \mathrm{MHz}, \mathrm{D}_{2} \mathrm{O}, 35^{\circ} \mathrm{C}\right)$ : $\delta=61.5\left(\mathrm{C}^{\prime}\right), 72.4\left(\mathrm{C}^{\prime}\right), 72.7\left(\mathrm{C}^{\prime}\right), 85.1\left(\mathrm{C}^{\prime}{ }^{\prime}\right), 88.4\left(\mathrm{C}^{\prime}\right), 107.1$ (C5), 149.4 (C4), 150.0 (C2), 153.9 (C8), 155.5 (C6) ppm. ${ }^{31} \mathrm{P}-\mathrm{NMR}$ $\left(300 \mathrm{MHz}, \mathrm{D}_{2} \mathrm{O}, 35^{\circ} \mathrm{C}\right): \delta=-10.7(\mathrm{~d}, J=9.7 \mathrm{~Hz}, \gamma-\mathrm{P}),-11.2(\mathrm{~d}$, $J=19.5 \mathrm{~Hz}, \alpha-\mathrm{P}),-23.1$ (t, $J=19.5 \mathrm{~Hz}, \beta-\mathrm{P}) \mathrm{ppm}$. HRMS (ESI): 521.98366 (calculated for $\mathrm{C}_{10} \mathrm{H}_{15} \mathrm{~N}_{5} \mathrm{O}_{14} \mathrm{P}_{3}: 521.98338$ ). Analytical HPLC (RP-C18, 4\% B [A=0.2 м TEAA, B=0.2 м TEAA:MeCN 95:5]): $9.85 \mathrm{~min}$.

8-Oxo-AMP was produced in situ during crystallization from 8oxo-ATP by unspecific nuclease activity. Addition of trace amounts of shrimp alkaline phosphatase was used to generate 8-oxo-adenosine from 8-oxo-ATP during crystallization. For ITC measurements, HPLC purified 8-oxo-adenosine was used (see below). As reported previously (Chatgilialoglu et al., 2006), NMR spectra did not show the tautomeric 8-hydroxy-adenosine, which would have the same hydrogen bonding potential as adenine.

\section{Protein purification and helicase assay}

The genes coding for authentic T. thermophilus Hera and TthDEAD were cloned as previously described (Rudolph et al., 2006; Linden et al., 2008). The Q28E mutation was introduced using the Quikchange (Qiagen, Hilden, Germany) procedure and the sequences were verified. Hera_Q28E and TthDEAD_Q28E were purified as described previously (Rudolph et al., 2006; Linden et al., 2008). After size exclusion chromatography (S200, GE Healthcare, Munich, Germany) in $50 \mathrm{~mm}$ Tris/ $\mathrm{HCl} \mathrm{pH} \mathrm{7.5,} 200 \mathrm{~mm} \mathrm{NaCl}$, TthDEAD_Q28E was concentrated to $2.23 \mathrm{~mm}$ by ultrafiltration (10 kDa MW cut-off, Millipore, Schwalbach, Germany) and stored at $-80^{\circ} \mathrm{C}$. Unwinding activity was measured using a $32 / 9$ mer RNA substrate derived from 23S rRNA as described (Linden et al., 2008) with $10 \mu \mathrm{M}$ Hera or Hera_Q28E, $5 \mu \mathrm{M}$ RNA, and $5 \mathrm{~mm}$ ATP or 8-oxo-ATP in $50 \mathrm{~mm}$ Tris/ $\mathrm{HCl} \mathrm{pH} 7.5,150 \mathrm{~mm} \mathrm{NaCl}, 5 \mathrm{mM} \mathrm{MgCl}_{2}$ at $25^{\circ} \mathrm{C}$ for $30 \mathrm{~min}$. Products were analyzed by native polyacrylamide gel electrophoresis.

\section{Crystallization, data collection, structure determination and refinement}

TthDEAD_Q28E was crystallized under similar conditions to wildtype TthDEAD (Rudolph et al., 2006) but these crystals did not diffract X-rays. A de novo search for crystallization conditions at $22^{\circ} \mathrm{C}$ in the sitting drop vapor diffusion setup yielded several conditions from a sparse matrix screen (Index, Hampton Research, Alison Viejo, CA, USA) that after adjustment resulted in three diffracting crystal forms. Tetragonal form I was grown by 1:1 mixing of 0.65-0.8 mM TthDEAD_Q28E with 20-25\% PEG3350 or PEG2000-MME, 0.2 $\mathrm{M} \mathrm{Li}_{2} \mathrm{SO}_{4}, 0.1 \mathrm{M}$ Tris/HCl pH 8.0-9.0. Triclinic form II was obtained by $1: 1$ mixing of $0.6 \mathrm{~mm}$ TthDEAD_Q28E and 15\% PEG3350, $0.2 \mathrm{M}$ sodium citrate, $0.1 \mathrm{M}$ HEPES/NaOH $\mathrm{pH}$ 7.5. A perfectly twinned hexagonal form III was obtained by $1: 1$ mixing of $0.6 \mathrm{~mm}$ TthDEAD_Q28E and $15 \%$ PEG3350, 0.2 м sodium malate, $0.1 \mathrm{~m}$ HEPES/NaOH pH 7.5. For nucleotide complexes a twofold molar excess of 8-oxo-ATP and $10 \mathrm{mM} \mathrm{MgCl}_{2}$ was added to the protein prior to crystallization. No complex with 8-oxo-ATP but complexes of TthDEAD_Q28E with partially hydrolyzed nucleotides were obtained. In the case of 8oxo-adenosine, hydrolysis was induced by adding trace amounts of alkaline phosphatase to crystallization trials containing 8-oxo-ATP, although 8-oxo-adenosine could have been used directly for co-crystallization. For the TthDEAD_Q28E complexes with 8-oxo-AMP and 8-oxo-ADP, the respective nucleotide was generated fortuitously in situ from 8-oxo-ATP without addition of phosphatase, incorporated into TthDEAD_Q28E during crystallization and identified based on electron density. Crystals were hyper-quenched (Warkentin and Thorne, 2007) in liquid nitrogen after dragging through paraffin oil. Data were collected at $100 \mathrm{~K}$ at beamlines PX-II and PX-III of the Swiss Light Source, reduced with XDS (Kabsch, 1988), and scaled with SCALA (CCP4, 1994, apo-forms) or SADABS (Bruker, ligand complexes). Tetragonal crystals (form I) were of space group 
$\mathrm{P}_{1} 2_{1} 2$ with two molecules in the asymmetric unit. The triclinic form II has four molecules per asymmetric unit and the twinned hexagonal crystal form III contains two molecules per asymmetric unit. All structures were determined by molecular replacement using the program PHASER (CCP4, 1994; McCoy et al., 2005) and PDBID 2gxs as search model (Rudolph et al., 2006). Models were built in COOT (Emsley et al., 2010) and refined with REFMAC5 (3MWJ and 3MWK) (CCP4, 1994) or PHENIX (all others) (Zwart et al., 2008 ) with $5 \%$ of reflections reserved for $R_{\text {free }}$ cross-validation (Brünger, 1992). The test set was kept consistent for data of the same Laue symmetry (3MWJ, 3MWL, 3MWK). For the twinned hexagonal data the test set was assigned in thin shells. The twin law and refined twin fraction are $-\mathrm{h},-\mathrm{k}, 1$ and 0.49 , respectively. The two-fold NCS axis for this structure is located at fractional coordinates $(0.5,0.47, \mathrm{z})$, close to a symmetry element of Laue group $6 / \mathrm{mmm}$, thus offering an explanation for the twinning. Data collection and refinement statistics are summarized in Table 1. Ligands were identified based on electron density and refined at full occupancy. No alternative conformations of the ligands were observed but parts of the ligands that are not contacted by protein atoms display elevated B-values. Figures were created with Bobscript (Esnouf, 1997) and Raster3D (Merritt and Murphy, 1994). Coordinates and structure factors were deposited in the Protein Data Bank with the accession number(s): $3 \mathrm{MWJ}, 3 \mathrm{MWK}, 3 \mathrm{MWL}, 3 \mathrm{NBF}$ and 3 NEJ.

\section{Isothermal titration calorimetry (ITC)}

Binding of 8-oxo-adenosine to TthDEAD_Q28E was determined at $298 \mathrm{~K}$ in $50 \mathrm{~mm}$ Tris/ $\mathrm{HCl} \mathrm{pH} \mathrm{7.5,} 200 \mathrm{~mm} \mathrm{NaCl}$ using an isothermal titration calorimeter (VP-ITC, MicroCal, Inc., Freiburg, Germany). 83.7 $\mu \mathrm{M}$ TthDEAD_Q28E in the cell was titrated with $8 \mu 1$ injections of a $1.907 \mathrm{~mm} 8$-oxo-adenosine solution. The concentration of 8-oxo-adenosine was determined by UV-spectroscopy using a molar extinction coefficient at $269 \mathrm{~nm}$ and $\mathrm{pH} 7.1$ of $\varepsilon_{269}=$ $15000 \mathrm{M}^{-1} \mathrm{~cm}^{-1}$ (Cho and Evans, 1991). ITC data were analyzed using the manufacturer's software based on a 1:1 stoichiometry as defined by the crystal structure.

\section{Acknowledgments}

We thank the staff at SLS beamlines PX-II and PX-III and Manuel Hilbert for support during data collection and Caroline Loew for help with the ITC measurement. This work was supported by grants from the Swiss National Science Foundation (to D.K.).

\section{References}

Andersen, C.B., Ballut, L., Johansen, J.S., Chamieh, H., Nielsen, K.H., Oliveira, C.L., Pedersen, J.S., Seraphin, B., Le Hir, H., and Andersen, G.R. (2006). Structure of the exon junction core complex with a trapped DEAD-box ATPase bound to RNA. Science 313, 1968-1972.

Benz, J., Trachsel, H., and Baumann, U. (1999). Crystal structure of the ATPase domain of translation initiation factor 4A from Saccharomyces cerevisiae - the prototype of the DEAD box protein family. Structure 7, 671-679.

Bono, F., Ebert, J., Lorentzen, E., and Conti, E. (2006). The crystal structure of the exon junction complex reveals how it maintains a stable grip on mRNA. Cell 126, 713-725.
Brünger, A.T. (1992). Free R value: a novel statistical quantity for assessing the accuracy of crystal structures. Nature 355, 472475.

Caruthers, J.M., Johnson, E.R., and McKay, D.B. (2000). Crystal structure of yeast initiation factor 4A, a DEAD-box RNA helicase. Proc. Natl. Acad. Sci. USA 97, 13080-13085.

CCP4 (1994). The Collaborative Computational Project Number 4, suite programs for protein crystallography. Acta Cryst. D50, 760-763.

Chatgilialoglu, C., Navacchia, M.L., and Postigo, A. (2006). A facile one-pot synthesis of 8-oxo-7,8-dihydro-(2'-deoxy)adenosine in water. Tetrahedron 47, 711-714.

Cho, B.P. and Evans, F.E. (1991). Structure of oxidatively damaged nucleic acid adducts. 3. Tautomerism, ionization and protonation of 8-hydroxyadenosine studied by ${ }^{15} \mathrm{~N}$ NMR spectroscopy. Nucleic Acids Res. 19, 1041-1047.

Collins, R., Karlberg, T., Lehtio, L., Schutz, P., van den Berg, S., Dahlgren, L.G., Hammarstrom, M., Weigelt, J., and Schuler, H. (2009). The DEXD/H-box RNA helicase DDX19 is regulated by an $\alpha$-helical switch. J. Biol. Chem. 284, 10296-10300.

Cordin, O., Banroques, J., Tanner, N.K., and Linder, P. (2006). The DEAD-box protein family of RNA helicases. Gene 367, 17-37.

Cordin, O., Tanner, N.K., Doere, M., Linder, P., and Banroques, J. (2004). The newly discovered Q motif of DEAD-box RNA helicases regulates RNA-binding and helicase activity. EMBO J. 23, 2478-2487.

Del Campo, M., Mohr, S., Jiang, Y., Jia, H., Jankowsky, E., and Lambowitz, A.M. (2009). Unwinding by local strand separation is critical for the function of DEAD-box proteins as RNA chaperones. J. Mol. Biol. 389, 674-693.

Draper, B. and Rao, V.B. (2007). An ATP hydrolysis sensor in the DNA packaging motor from bacteriophage T4 suggests an inchworm-type translocation mechanism. J. Mol. Biol. 369, 79-94.

Emsley, P., Lohkamp, B., Scott, W.G., and Cowtan, K. (2010). Features and development of Coot. Acta Cryst. D66, 486-501.

Esnouf, R.M. (1997). An extensively modified version of MOLSCRIPT that includes greatly enhanced coloring capabilities. J. Mol. Graph. 15, 132-134.

Evans, P. (2006). Scaling and assessment of data quality. Acta Cryst. $62,72-82$

Grohman, J.K., Del Campo, M., Bhaskaran, H., Tijerina, P., Lambowitz, A.M., and Russell, R. (2007). Probing the mechanisms of DEAD-box proteins as general RNA chaperones: the C-terminal domain of CYT-19 mediates general recognition of RNA. Biochemistry 46, 3013-3022.

Hilbert, M., Karow, A.R., and Klostermeier, D. (2009). The mechanism of ATP-dependent RNA unwinding by DEAD box proteins. Biol. Chem. 390, 1237-1250.

Hilbert, M., Kebbel, F., Gubaev, A., and Klostermeier, D. (2010). eIF4G stimulates the activity of the DEAD box protein eIF4A by a conformational guidance mechanism. Nucleic Acids Res., in revision. In press, PMID 21062831

Hoffenberg, S., Nikolova, L., Pan, J.Y., Daniel, D.S., Wessling-Resnick, M., Knoll, B.J., and Dickey, B.F. (1995). Functional and structural interactions of the Rab5 D136N mutant with xanthine nucleotides. Biochem. Biophys. Res. Commun. 215, 241-249.

Högbom, M., Collins, R., van den Berg, S., Jenvert, R.M., Karlberg, T., Kotenyova, T., Flores, A., Karlsson Hedestam, G.B., and Schiavone, L.H. (2007). Crystal structure of conserved domains 1 and 2 of the human DEAD-box helicase DDX3X in complex with the mononucleotide AMP. J. Mol. Biol. 372, 150-159.

Hwang, Y.W. and Miller, D.L. (1987). A mutation that alters the nucleotide specificity of elongation factor Tu, a GTP regulatory protein. J. Biol. Chem. 262, 13081-13085. 
Iyer, L.M., Makarova, K.S., Koonin, E.V., and Aravind, L. (2004). Comparative genomics of the FtsK-HerA superfamily of pumping ATPases: implications for the origins of chromosome segregation, cell division and viral capsid packaging. Nucleic Acids Res. 32, 5260-5279.

Johnson, E.R. and McKay, D.B. (1999). Crystallographic structure of the amino terminal domain of yeast initiation factor $4 \mathrm{~A}$, a representative DEAD-box RNA helicase. RNA 5, 1526-1534.

Jones, S., Litt, R.J., Richardson, C.J., and Segev, N. (1995). Requirement of nucleotide exchange factor for Ypt1 GTPase mediated protein transport. J. Cell Biol. 130, 1051-1061.

Kabsch, W. (1988). Evaluation of single crystal x-ray diffraction data from a position sensitive detector. J. Appl. Cryst. 21, 916924.

Kang, C., Sun, N., Honzatko, R.B., and Fromm, H.J. (1994). Replacement of Asp333 with Asn by site-directed mutagenesis changes the substrate specificity of Escherichia coli adenylosuccinate synthetase from guanosine 5'-triphosphate to xanthosine 5'-triphosphate. J. Biol. Chem. 269, 24046-24049.

Kim, J.L., Morgenstern, K.A., Griffith, J.P., Dwyer, M.D., Thomson, J.A., Murcko, M.A., Lin, C., and Caron, P.R. (1998). Hepatitis $\mathrm{C}$ virus NS3 RNA helicase domain with a bound oligonucleotide: the crystal structure provides insights into the mode of unwinding. Structure 6, 89-100.

Klostermeier, D. and Rudolph, M.G. (2009). A novel dimerization motif in the C-terminal domain of the Thermus thermophilus DEAD box helicase Hera confers substantial flexibility. Nucleic Acids Res. 37, 421-430.

Kossen, K., Karginov, F.V., and Uhlenbeck, O.C. (2002). The carboxy-terminal domain of the DExDH protein YxiN is sufficient to confer specificity for 23S rRNA. J. Mol. Biol. 324, 625-636.

Laskowski, R.A., MacArthur, M.W., Moss, D.S., and Thornton, J.M. (1993). PROCHECK: a program to check the stereochemical quality of protein structures. J. Appl. Cryst. 26, 283-291.

Linden, M.H., Hartmann, R.K., and Klostermeier, D. (2008). The putative RNase P motif in the DEAD box helicase Hera is dispensable for efficient interaction with RNA and helicase activity. Nucleic Acids Res. 36, 5800-5811.

McCoy, A.J., Grosse-Kunstleve, R.W., Storoni, L.C., and Read, R.J. (2005). Likelihood-enhanced fast translation functions. Acta Cryst. D61, 458-464.

Merritt, E.A. and Murphy, M.E.P. (1994). Raster3D Version 2.0 a program for photorealistic molecular graphics. Acta Cryst. D50, 869-873.

Mohr, G., Del Campo, M., Mohr, S., Yang, Q., Jia, H., Jankowsky, E., and Lambowitz, A.M. (2008). Function of the C-terminal domain of the DEAD-box protein Mss116p analyzed in vivo and in vitro. J. Mol. Biol. 375, 1344-1364.

Morlang, S., Weglohner, W., and Franceschi, F. (1999). Hera from Thermus thermophilus: the first thermostable DEAD-box helicase with an RNase P protein motif. J. Mol. Biol. 294, 795805.

Powers, T. and Walter, P. (1995). Reciprocal stimulation of GTP hydrolysis by two directly interacting GTPases. Science 269, 1422-1424.

Rudolph, M.G., Heissmann, R., Wittmann, J.G., and Klostermeier, D. (2006). Crystal structure and nucleotide binding of the Thermus thermophilus RNA helicase Hera N-terminal domain. J. Mol. Biol. 361, 731-743.

Rudolph, M.G. and Klostermeier, D. (2009). The Thermus thermophilus DEAD box helicase Hera contains a modified RNA recognition motif domain loosely connected to the helicase core. RNA 15, 1993-2001.
Rybin, V., Ullrich, O., Rubino, M., Alexandrov, K., Simon, I., Seabra, M.C., Goody, R., and Zerial, M. (1996). GTPase activity of Rab5 acts as a timer for endocytic membrane fusion. Nature 383, 266-269.

Schütz, P., Bumann, M., Oberholzer, A.E., Bieniossek, C., Trachsel, H., Altmann, M., and Baumann, U. (2008). Crystal structure of the yeast eIF4A-eIF4G complex: an RNA-helicase controlled by protein-protein interactions. Proc. Natl. Acad. Sci. USA 105, 9564-9569.

Schutz, P., Karlberg, T., van den Berg, S., Collins, R., Lehtio, L., Hogbom, M., Holmberg-Schiavone, L., Tempel, W., Park, H.W., Hammarstrom, M., et al. (2010). Comparative structural analysis of human DEAD-box RNA helicases. PLoS One 5.

Sengoku, T., Nureki, O., Nakamura, A., Kobayashi, S., and Yokoyama, S. (2006). Structural basis for RNA unwinding by the DEAD-Box protein Drosophila Vasa. Cell 125, 287-300.

Shi, H., Cordin, O., Minder, C.M., Linder, P., and Xu, R.M. (2004). Crystal structure of the human ATP-dependent splicing and export factor UAP56. Proc. Natl. Acad. Sci. USA 101, 1762817633.

Story, R.M. and Steitz, T.A. (1992). Structure of the recA proteinADP complex. Nature 355, 374-376.

Story, R.M., Weber, I.T., and Steitz, T.A. (1992). The structure of the E. coli recA protein monomer and polymer. Nature 355, $318-325$.

Tanner, N.K. (2003). The newly identified Q motif of DEAD box helicases is involved in adenine recognition. Cell Cycle 2, $18-19$.

Tanner, N.K., Cordin, O., Banroques, J., Doere, M., and Linder, P. (2003). The Q motif: a newly identified motif in DEAD box helicases may regulate ATP binding and hydrolysis. Mol. Cell $11,127-138$.

Tsay, J.M., Sippy, J., Feiss, M., and Smith, D.E. (2009). The Q motif of a viral packaging motor governs its force generation and communicates ATP recognition to DNA interaction. Proc. Natl. Acad. Sci. USA 106, 14355-14360.

Tsu, C.A., Kossen, K., and Uhlenbeck, O.C. (2001). The Escherichia coli DEAD protein DbpA recognizes a small RNA hairpin in $23 \mathrm{~S}$ rRNA. RNA 7, 702-709.

von Moeller, H., Basquin, C., and Conti, E. (2009). The mRNA export protein DBP5 binds RNA and the cytoplasmic nucleoporin NUP214 in a mutually exclusive manner. Nat. Struct. Mol. Biol. 16, 247-254.

Warkentin, M. and Thorne, R.E. (2007). A general method for hyperquenching protein crystals. J. Struct. Funct. Genomics 8 , $141-144$.

Weijland, A., Sarfati, R., Barzu, O., and Parmeggiani, A. (1993). Asparagine-135 of elongation factor Tu is a crucial residue for the folding of the guanine nucleotide binding pocket. FEBS Lett. $330,334-338$.

Yao, N., Hesson, T., Cable, M., Hong, Z., Kwong, A.D., Le, H.V., and Weber, P.C. (1997). Structure of the hepatitis C virus RNA helicase domain. Nat. Struct. Biol. 4, 463-467.

Yu, B., Slepak, V.Z., and Simon, M.I. (1997). Characterization of a $\mathrm{G}_{\mathrm{o}} \alpha$ mutant that binds xanthine nucleotides. J. Biol. Chem. 272, 18015-18019.

Zhong, J.M., Chen-Hwang, M.C., and Hwang, Y.W. (1995). Switching nucleotide specificity of Ha-Ras p21 by a single amino acid substitution at aspartate 119. J. Biol. Chem. 270, 10002-10007.

Zwart, P.H., Afonine, P.V., Grosse-Kunstleve, R.W., Hung, L.W., Ioerger, T.R., McCoy, A.J., McKee, E., Moriarty, N.W., Read, R.J., Sacchettini, J.C., et al. (2008). Automated structure solution with the PHENIX suite. Methods Mol. Biol. 426, 419-435.

Received September 21, 2010; accepted November 30, 2010 